\title{
Effects of Temperature upon Water Turnover in Fish Ponds in Northern Thailand
}

\author{
Patcharawalai Sriyasak $^{1,2}$, Chanagun Chitmanat ${ }^{1}$, Niwooti Whangchai ${ }^{1}$, \\ Jongkon Promya ${ }^{1}$, Louis Lebel ${ }^{2}$ \\ ${ }^{1}$ Faculty of Fisheries Technology and Aquatic Resources, Maejo University, Chiang Mai, Thailand \\ ${ }^{2}$ Unit for Social and Environmental Research (USER), Faculty of Social Science, Chiang Mai University, Chiang Mai, Thailand \\ Email: louis@sea-user.org
}

Received June 2013

\begin{abstract}
Fish culture in earthen ponds is an important source of income for farmers in northern Thailand. Water quality in ponds has strong impacts on fish production farmers' return and is sensitive to weather and climate. Low levels of dissolved oxygen in fish ponds are major cause of mass mortality. Stratification with depth in ponds followed by rapid turnover or exchange of surface and bottom water can expose fish to dangerously low dissolved oxygen levels. The main purpose of this study was to observe the effects of weather on stratification and subsequent water turnover in fish ponds in northern Thailand, especially in the winter and rainy season, when stratification was expected to be most severe. Temperature and water quality measurements were made in fish ponds at 18 farms with depths ranged from $0.8-2.0 \mathrm{~m}$ and size of 0.16 - 0.64 ha. Measurements were made during January and May 2013. Fish farm pond sites were divided into two groups based on elevation above sea level: low ( $<400$ masl) and high ( $>400$ masl) and categorized into 3 types of farming: commercial, integrated and subsistence. In lower elevation sites, water turnover occurred at night between 22.00 and 02.00 in winter and between 18.00 and 02.00 in rainy season. At higher elevation, turnover occurred in ponds between 20.00 and 22.00 in winter and between 14.00 and 18.00 in rainy season. Turnover was slower in the lower elevation than in higher elevation zones and generally occurred earlier during the rainy season than in the winter. Mean DO in winter was significantly higher $(\mathrm{p}<0.05)$ than in rainy season, whilst water temperature and amount of ammonia-nitrogen during the rainy season was significantly higher $(\mathrm{p}<0.05)$ than in winter. Turnover improves distribution of dissolved oxygen through the water column and minimizes organic matter accumulation. Cloud cover during the rainy season may have contributed to limit oxygen production and thus may have significantly affect water quality in ponds. Fish farmers should consider more explicitly the role of temperature and cloud conditions when managing dissolved oxygen levels in their fish ponds. Therefore, efficient pond aeration or pond mixing strategies for reducing stratification still plays an important component for providing sound pond management in tilapia production ponds.
\end{abstract}

Keywords: Climate; Temperature; Oxygen; Turnover; Fish Culture

\section{Introduction}

Tilapia fish culture in earthen ponds is expanding dramatically in Thailand [1]. Farmers, especially in the northern area raise these popular freshwater fish under intensive or extensive methods, in pond cages and most commonly along with livestock under the integrated farming scheme for local consumption and livelihood. Currently, fish farmers face difficulties in rearing tilapia in earthen ponds. Warmer pond temperatures due to climate change may be a contributing factor to this problem. Temperature and dissolved oxygen (DO) have impacts on fish production $[2,3]$ and may be affected by weather and climate $[4,5]$. Prolonged extreme hot weather followed by a heavy rain disturbs the surface water to cool lower temperatures where the cool heavy water layer sink to the bottom floor due to gravity can cause turnover of water in ponds [6,7]. Stratification with depth in ponds followed by rapid turnover or exchange of surface and bottom water can expose fish to dangerously low dissolved oxygen levels subjecting them to stress and vulnerability to diseases. Low levels of dissolved oxygen in fish ponds are major cause of fish death [8]. Tilapia fish culture in earthen ponds in northern Thailand can be divided into three categories: commercial, integrated (with pig or chicken) and subsistence. Sensitivity to lower dissolved oxygen in different culture systems causes different levels of risks of mortality from changes in weather and water turnover. The main purpose of this study was to measure the effects of weather on stratification and subsequent water turnover in fish ponds under different 
culture systems and in different sites across a climate gradient in northern Thailand so as to identify ways to reduce risks of mass mortality under current climate as well as adapt to a changing climate.

\section{Material and Methods}

\subsection{Study Site}

This study was carried out in 18 ponds located in 5 selected provinces of Northern Thailand: Chiangrai, Chiangmai, Phayao, Lampang and Nakornsawan. Mean elevation of these areas range from 25 to 582 meters above sea level (masl). Pond sizes ranged from $0.16-0.64$ ha with depths of $0.8-2.0 \mathrm{~m}$. Ponds were grouped according to elevation (lower, $<400$ masl and higher, $>400$ masl) and culture system: commercial (C), where prepared pellet feed was regularly provided and crops tended to be harvested at one-time and sold; integrated (I), where fish and livestock were being raised in the same area; and subsistence (S), where feeding was sporadic and fish harvested continuously for consumption and market. The characteristics of each of culture system are further described and summarized in Table $\mathbf{1}$.

\subsection{Water Parameter}

Data of water quality in ponds were collected for a typical winter and rainy months, January and May 2013. Water temperature, dissolved oxygen (DO), $\mathrm{pH}$, turbidity and conductivity were monitored at 2-hour interval over a 24-hour period in each season at every 20-cm depth with a multimeter (TOA DKK WQC-22A model, Japan). Water samples were collected $20-\mathrm{cm}$ below the surface and $20-\mathrm{cm}$ just off the bottom using a modified water sampler. Chemical analyses were carried out for Total Ammonia-Nitrogen (TAN), Nitrite-Nitrogen $\left(\mathrm{NO}_{2}^{-}-\mathrm{N}\right)$, Nitrate-Nitrogen $\left(\mathrm{NO}_{3}^{-}-\mathrm{N}\right)$, Orthophosphate $\left(\mathrm{PO}_{4}^{3-}-\mathrm{P}\right)$, Alkalinity, Total Suspended Solids (TSS) and Chloro- phyll-a (Chl-a) according to standard methods [9].

\subsection{Statistical Analysis}

ANOVA was used to compare water pond parameters across the two elevation groups and the three culture systems. Paired sample T-test was used to compare the differences of water quality variables between the two seasons at $\mathrm{p}<0.05$.

\section{Results and Discussion}

\subsection{Temperature Measurements at Sampling Sites}

Mean air and water temperatures decrease with mean elevation across the climate gradient of sites selected for study (Figure 1). Expectedly, observed air and water temperatures were lower at higher elevation sites. Bihourly variation of air temperature in the winter (January) ranged between $16.5^{\circ} \mathrm{C}$ and $35.83^{\circ} \mathrm{C}(28.3 \pm 4.11)$ and water temperature, between $25.5^{\circ} \mathrm{C}$ to $27.1^{\circ} \mathrm{C}$ (26.3 \pm 0.57). Monitored bi-hourly air temperature during the rainy season (May) ranged between $22.0^{\circ} \mathrm{C}$ and $37.3^{\circ} \mathrm{C}$ (28.14 \pm 4.03$)$ and water temperature, between $29.4^{\circ} \mathrm{C}$ to $31.8^{\circ} \mathrm{C}(30.44 \pm 0.80)$. Altitude affects the temperature of the air because air pressure gets lower as the altitude increases and so does inversely affect pond water temperature as well.

Table 1. Major properties of ponds monitored in the study.

\begin{tabular}{cccc}
\hline \multirow{2}{*}{ Pond Property } & \multicolumn{3}{c}{ Culture System } \\
\cline { 2 - 4 } & Commercial (C) & Integrated (I) & Subsistence (S) \\
\hline Pond Area $\left(\mathrm{m}^{2}\right)$ & $1600-3200$ & $1600-4800$ & $640-1280$ \\
Pond Depth (m) & $1.20-1.80$ & $1.20-1.50$ & $0.80-1.50$ \\
$\begin{array}{c}\text { Stocking Rate } \\
\left(\text { fish } \mathrm{m}^{-2} \text { ) }\right.\end{array}$ & 3 & 3 & $0.5-1$ \\
Culture Period (d) & $30-90$ & $30-120$ & $120-240$ \\
Water Renewal & $10 \%$ per day & seldom & No renewal \\
\hline
\end{tabular}

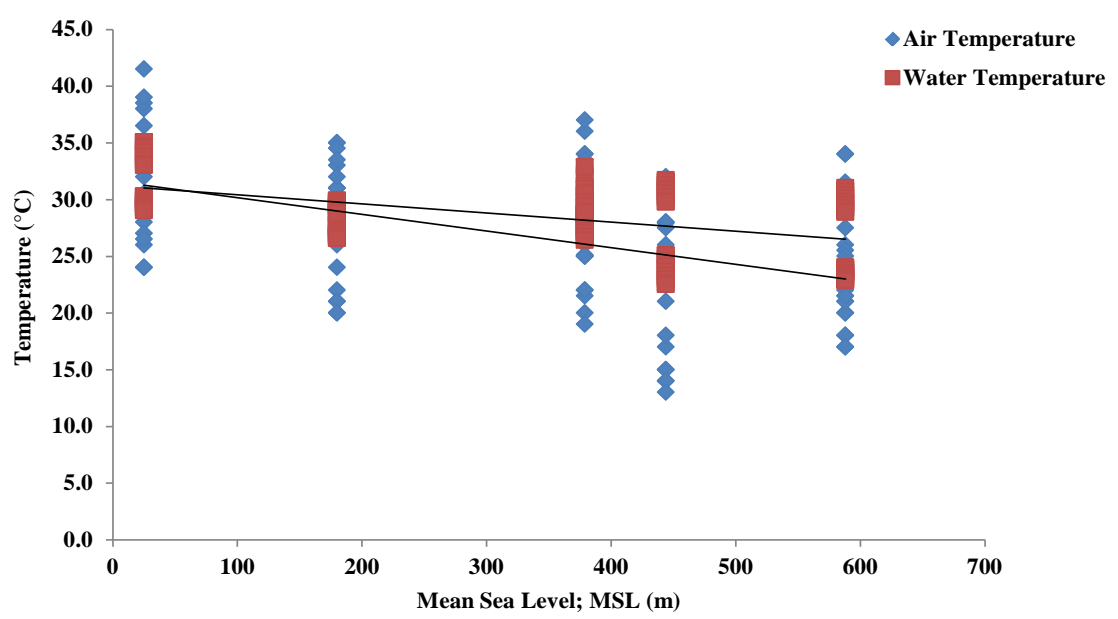

Figure 1. Air and water temperatures at different elevations above sea level. 


\subsection{Water Turnover in Ponds}

All ponds monitored stratify diurnally. During the night and at pre-dawn the water column is isothermal, over mid-day it is thermally stratified but isothermal conditions return with the onset of light evening winds. Maximum temperature was recorded at around mid-afternoon (15:00) in all ponds irrespective of elevation and culture system type, which is typical in a shallow aquaculture pond system.

Integrated plots of dissolved oxygen, air and water temperatures of ponds at lower elevation ( $<400$ masl) for the two seasons are shown in Figures 2(a) and 2(b). Mean air and water temperatures in the winter ranged from $21^{\circ} \mathrm{C}$ to $35.8^{\circ} \mathrm{C}(27.9 \pm 5.2)$ and from $27.4^{\circ} \mathrm{C}$ to $29.0^{\circ} \mathrm{C}(28.3 \pm 0.53)$, respectively. Mean surface DO fluctuated between 1.05 and $11.72 \mathrm{mg} \cdot \mathrm{L}^{-1}(5.38 \pm 3.84)$. Maximum DO value was at 16:00 daylight hour while the minimum values were observed at dawn (4:00 - 6:00) which coincided with bottom DO concentration minimums. Pond bottom DO fluctuated between 0.97 and $4.13 \mathrm{mg} \cdot \mathrm{L}^{-1}(2.25 \pm 1.10)$ which reaches its maximum at 20:00. Noteworthy, water turnover of ponds in the winter occurred at 20:00 when bottom DO was at its maximum. Complete destratification and mixing occurred at 4:00 until 6:00 when surface and bottom DO were almost equal and at nearly isothermal condition. On the other hand, mean air and water temperatures recorded for the rainy season (May) were from $27.2^{\circ} \mathrm{C}$ to $37.3^{\circ} \mathrm{C}(31.1 \pm$ $3.5)$ and from $28.7^{\circ} \mathrm{C}$ to $29.9^{\circ} \mathrm{C}(30.5 \pm 0.90)$,
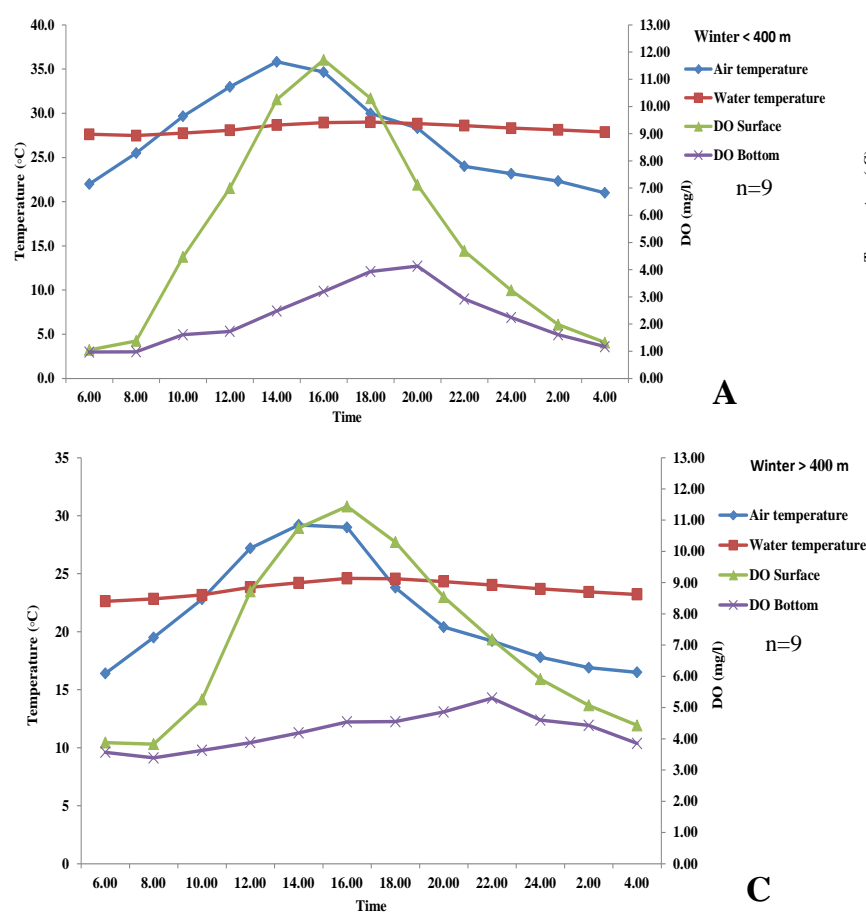

respectively. Mean range of surface DO was from 0.43 to $14.69 \mathrm{mg} \cdot \mathrm{L}^{-1}(4.93 \pm 4.89)$ whereas the mean DO range at the bottom was from 0.30 to $2.9 \mathrm{mg} \cdot \mathrm{L}^{-1}(0.94 \pm 0.78)$. Water turnover transition occurred between 18:00 - 02:00. when surface DO started to drop significantly and bottom DO reaches its maximum and decreases thereafter. Isothermal condition and complete destratification were attained at 4:00 until 6:00 as observed in the winter. However, water turnover occurred earlier for the rainy season as compared during the winter. This could be due to rain effect, cooling the surface water by a cold rain and wind close to the temperature of deep water, allowing them to mix.

In higher elevation sites (>400 masl) (Figures 2(c), 2(d)), mean air and water temperatures during the winter was recorded to be between $16.4^{\circ} \mathrm{C}$ to $29.2^{\circ} \mathrm{C}(21.6 \pm$ 4.78) and between $22.9^{\circ} \mathrm{C}$ to $24.5^{\circ} \mathrm{C}(23.7 \pm 0.62)$, respectively. Mean surface DO fluctuated from 3.83 to $11.44 \mathrm{mg} \cdot \mathrm{L}^{-1}(7.11 \pm 2.77)$ while the mean bottom DO ranged from 3.39 to $5.30 \mathrm{mg} \cdot \mathrm{L}^{-1}(4.23 \pm 0.58)$. In rainy season, mean air and water temperatures ranged from 23.3 ${ }^{\circ} \mathrm{C}$ to $29.8^{\circ} \mathrm{C}(25.7 \pm 2.7)$ and from $29.4^{\circ} \mathrm{C}$ to $31.4^{\circ} \mathrm{C}$ (30.4 \pm 0.70$)$, respectively. Mean surface DO was 1.36 to $10.88 \mathrm{mg} \cdot \mathrm{L}^{-1}(5.32 \pm 3.21)$ and the mean bottom DO varied from 1.17 to $6.46 \mathrm{mg} \cdot \mathrm{L}^{-1}(3.42 \pm 2.07)$. The same pattern was observed in both higher and lower elevation sites with respect to the relative difference in water turnover occurrence between the two seasons, except only that the difference is more pronounced in the former. Water turnover in higher elevation sites occurred at 22:00 in the
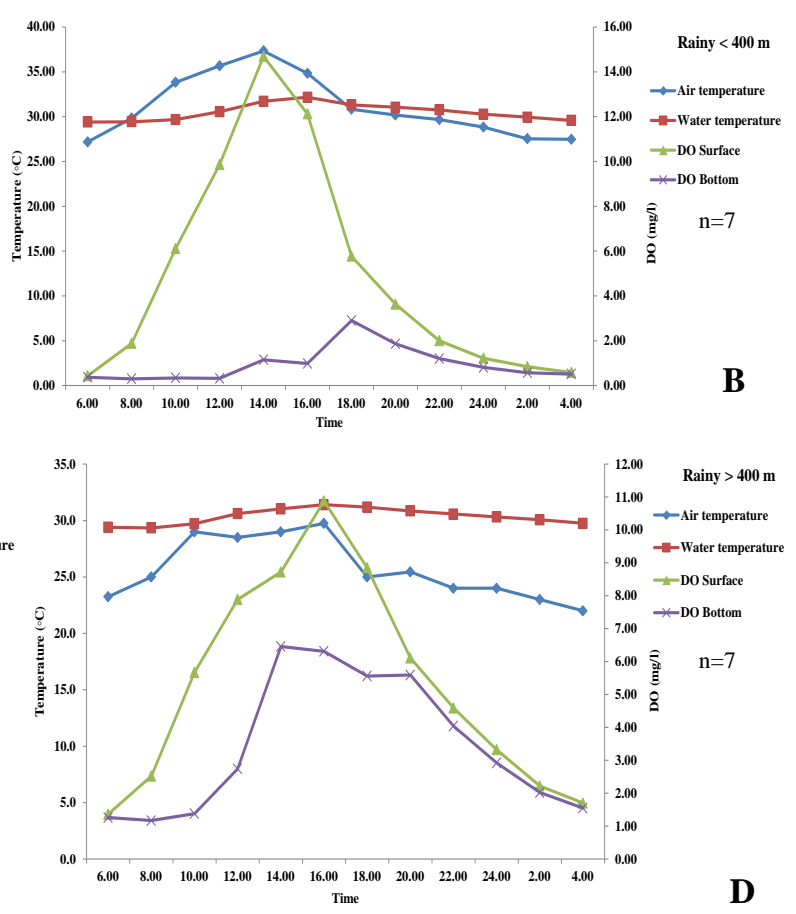

Figure 2. Air and water temperatures, surface and bottom DO at elevations of sea level and in winter and rainy season. 
winter. For the rainy season, the water turnover occurred during daylight at 14.00 and 18.00 p.m. Due to heavy rain during that time the water on the floor mixed with water then sinking with lower water in the rain (Figure 2). Apparently, isothermal condition and full turnover for both seasons at higher elevation also occurred at around 6:00 which is similar in lower elevation sites.

\subsection{Water Quality in Ponds in Different Seasons}

Mean values of water quality parameters for the two seasons are presented in Table 2. Mean DO in winter was significantly higher than in rainy season, whilst water temperature and amount of ammonia-nitrogen during the rainy season was significantly higher than in the winter. It was expected though to find higher concentrations of DO in ponds during cold winter months. Cold water (lower temperature) has a higher solubility to dissolved gases than warm water does. A possible explanation for the lower mean DO values in the rainy season could be partly due to cloud cover limiting sunlight to reach the water surface, thus affects photosynthesis and oxygen production. Another is the turbidity nature of the water at this period due to inflows from localized run-offs and decomposition of organic matter in the water. Moreover, ammonia and other partially degraded decomposition products are released during the aerobic decomposition process therefore contributed to significantly higher ammonia-nitrogen concentration in rainy season.

Table 2. Physico-chemical and biological characteristics of monitored ponds by season.

\begin{tabular}{|c|c|c|}
\hline \multirow[t]{2}{*}{ Variables } & \multicolumn{2}{|c|}{ Season } \\
\hline & Winter & Rainy \\
\hline Temperature $\left({ }^{\circ} \mathrm{C}\right)$ & $26.0 \pm 2.34^{\mathrm{a}}$ & $30.4 \pm 1.350^{\mathrm{b}}$ \\
\hline $\mathrm{pH}$ & $7.25 \pm 0.69$ & $7.24 \pm 3.34$ \\
\hline $\mathrm{DO}\left(\mathrm{mg} \cdot \mathrm{L}^{-1}\right)$ & $4.81 \pm 1.83^{\mathrm{a}}$ & $3.39 \pm 1.78^{\mathrm{b}}$ \\
\hline Conductivity $\left(\mathrm{mScm}^{-1}\right)$ & $32.30 \pm 26.95$ & $35.52 \pm 28.17$ \\
\hline Turbidity (NTU) & $82.50 \pm 46.97$ & $107.32 \pm 77.42$ \\
\hline Chlorophyll-a $\left(\mu \mathrm{g} \cdot \mathrm{L}^{-1}\right)$ & $209.61 \pm 185.23$ & $212.22 \pm 226.71$ \\
\hline $\mathrm{NH}_{4}-\mathrm{N}\left(\mathrm{mg} \cdot \mathrm{L}^{-1}\right)$ & $0.188 \pm 0.15^{\mathrm{a}}$ & $0.415 \pm 0.35^{\mathrm{b}}$ \\
\hline $\mathrm{NO}_{2}-\mathrm{N}\left(\mathrm{mg} \cdot \mathrm{L}^{-1}\right)$ & $0.014 \pm 0.17$ & $0.026 \pm 0.04$ \\
\hline $\mathrm{NO}_{3}-\mathrm{N}\left(\mathrm{mg} \cdot \mathrm{L}^{-1}\right)$ & $0.028 \pm 0.03$ & $0.090 \pm 0.14$ \\
\hline $\mathrm{PO}_{4}{ }^{3}-\mathrm{P}\left(\mathrm{mg} \cdot \mathrm{L}^{-1}\right)$ & $0.105 \pm 0.21$ & $0.058 \pm 0.09$ \\
\hline Alkalinity $\left(\mathrm{mg} \cdot \mathrm{L}^{-1}\right.$ ) & $319.85 \pm 262.77$ & $222.94 \pm 137.84$ \\
\hline $\mathrm{TSS}\left(\mathrm{mg} \cdot \mathrm{L}^{-1}\right)$ & $55.08 \pm 27.16$ & $55.73 \pm 25.68$ \\
\hline
\end{tabular}

Means followed by different letters are significantly different according to paired t-test at $\mathrm{p}<0.05$.
No significant difference was observed for the other water quality parameters among sampling times. Moreover, all water quality parameters analyzed were generally within the acceptable range for fish culture.

\subsection{Effects of Elevation, Culture Type and Season on Water Quality}

Multifactor-ANOVA was used to analyze the difference of water quality in ponds at different elevation, fish culture systems and season. There were 4 main patterns observed. First there was significant interaction between elevation, culture system and season for alkalinity, conductivity, turbidity and chlorophyll a (Figure 3). Commercial farms have high temperature, TAN, alkalinity and conductivity at altitudes $<400 \mathrm{~m}$, but not the other two culture systems. Second, DO was lower and TAN, turbidity and TSS were higher in ponds in the higher elevation group. Third, integrated culture systems had higher turbidity, TSS and Chl-a than commercial and subsistence culture systems; whereas commercial farms have relatively high TAN and subsistence farms had higher $\mathrm{NO}_{2}^{-}-\mathrm{N}$ and $\mathrm{NO}_{3}^{-}-\mathrm{N}$. Fourth, TAN, $\mathrm{NO}_{2}^{-}-\mathrm{N}$ and $\mathrm{NO}_{3}^{-}-\mathrm{N}$ were higher in rainy season, while $\mathrm{pH}$ and conductivity were higher in winter. For all other water parameters no significant differences were detected.

\subsection{Pond Bottom Dissolved Oxygen}

Measured DO concentration at the bottom of the pond during winter was higher than the threshold value for Nile tilapia $\left(0.8 \mathrm{mg} \cdot \mathrm{L}^{-1}\right.$ at $\left.26^{\circ} \mathrm{C}\right)(3)$ at all times and in all three culture systems (Figure 4(a)). DO in commercial ponds was consistently lower than in other culture systems, but tended to vary more in integrated than subsistence ponds over the 24-hour cycle. DO at the bottom of the pond during rainy in commercial and integrated systems were lower than the threshold of DO from midnight to $10: 00$, whereas in subsistence farms it was always above the threshold of DO (Figure 4(b)).

Commercial and integrated culture systems have higher risk of low oxygen concentration than subsistence systems because both of these systems have higher fish stocking density and feeding rate. The amount of organic matter and waste (including excess uneaten feeds) are expectedly high for these systems, depleting water of DO during the decomposition of these materials at the bottom.

\subsection{Limitations and Future Research}

This study had some important limitations that raise questions for future research. First, the observations were based on single dates in each season. Stronger evidence about effects of season requires multiple observations 

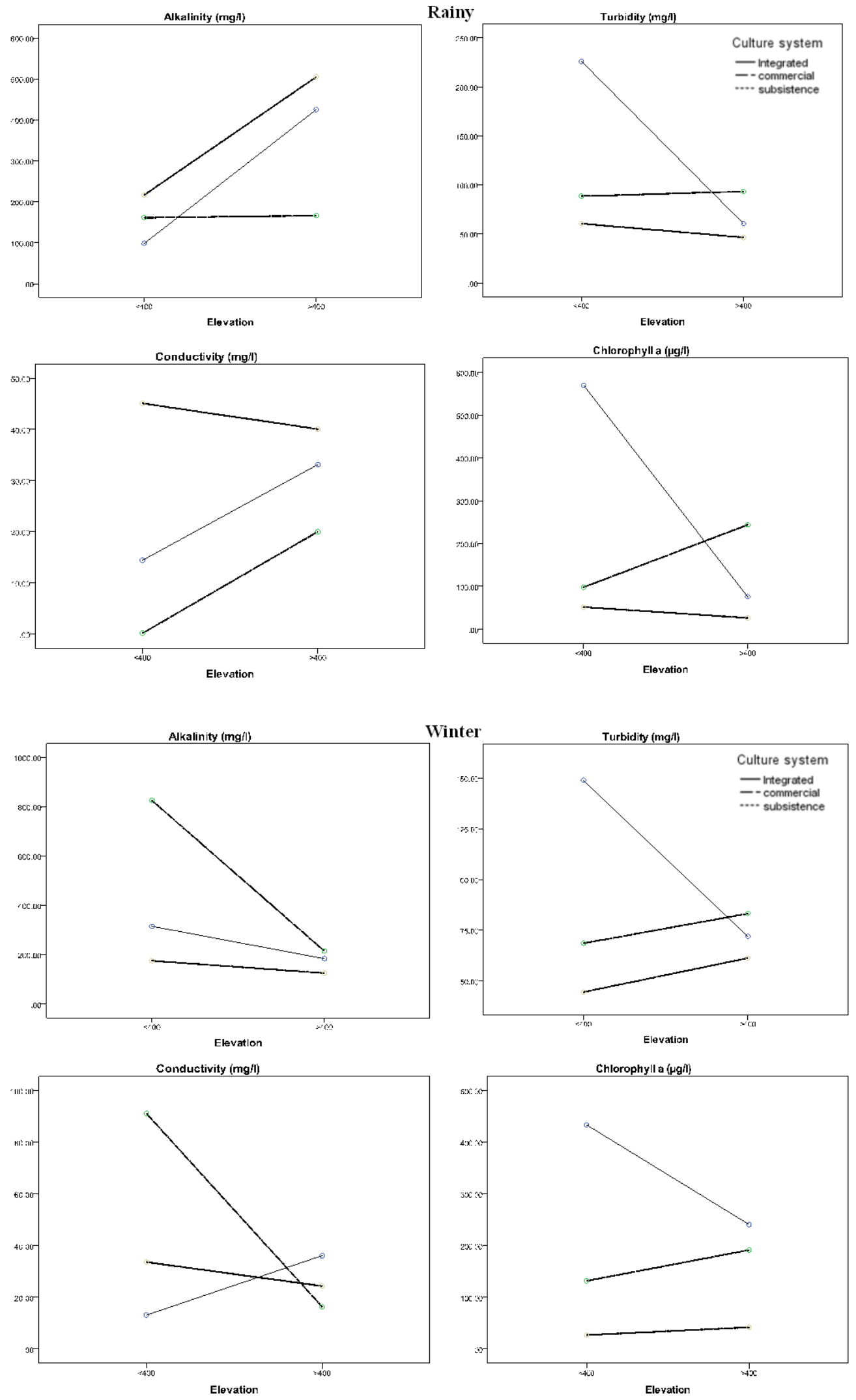

Figure 3. Water quality in ponds at different elevation and fish culture in $\mathbf{2}$ seasons. 

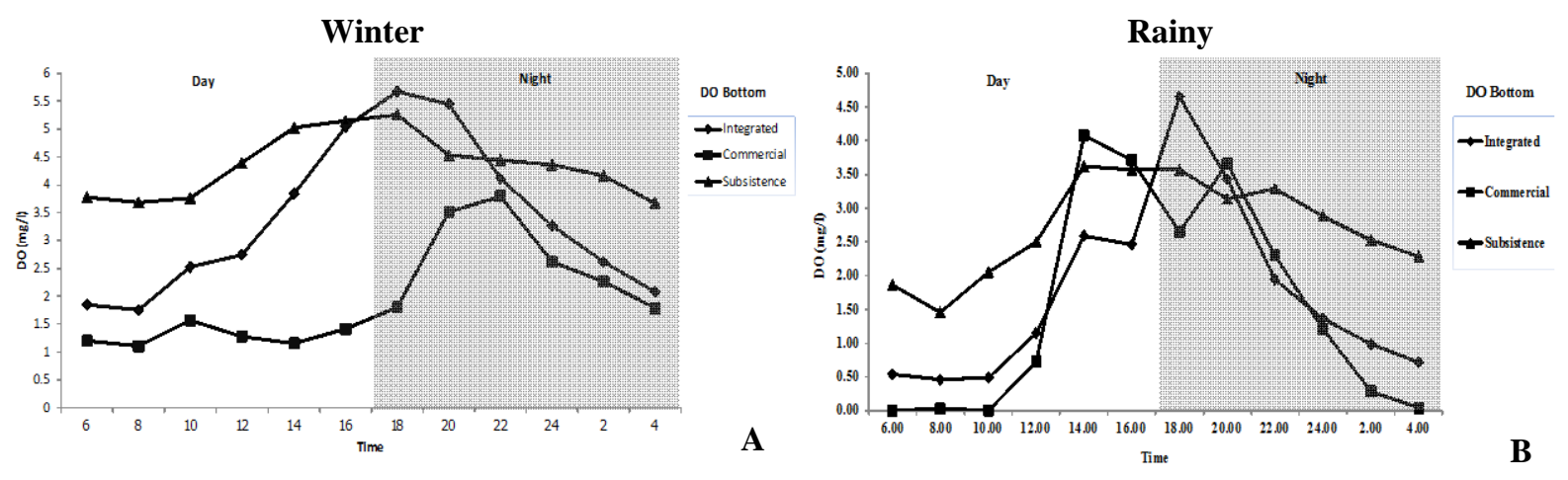

Figure 4. Water quality in ponds at different elevation and fish culture in 2 seasons; (A) DO bottom in winter; (B) DO bottom in rainy season.

within seasons, and ideally, from more than one year. Second, the effects of rainfall, wind and other weather-related phenomenon proposed as causal mechanisms for water turn-over patterns also require further research.

\section{Conclusion}

Elevation and season affect water turnover in tilapia fish ponds. At higher elevations in the rainy season water turnover occurs earlier probably because relatively cooler rain lowers surface water temperature and associated wind together increases circulation. Counter-intuitively in the rainy season there is a greater risk of low levels of dissolved oxygen, higher temperature and more TAN as well as $\mathrm{NO}_{2}^{-}-\mathrm{N}$ and $\mathrm{NO}_{3}^{-}-\mathrm{N}$ in fish ponds than in winter. Commercial farms appeared to be more prone to climate-related problems due to their relatively higher temperature, TAN, alkalinity and conductivity at lower elevation. Higher elevation ponds were likewise affected with lower DO, TAN, turbidity and TSS. Therefore, commercial (and integrated) farmers situated at higher altitudes should adapt sound and effective fish culture strategies (feed and waste reduction; use of aerators and pond mixers) to maintain safe levels of DO in the pond and reduce the risks of fish production losses from extreme weather and to help build resilience to climate variability and change

\section{Acknowledgements}

The work was carried out with the aid of a grant from the International Development Research Centre, Ottawa, Canada, as a contribution to the AQUADAPT project. Special thanks to Redel Gutierrez of Maejo University for editing this paper.

\section{REFERENCES}

[1] DOF, “Tilapia Development Strategy (2510-2514),” Department of Fisheries, Ministry of Agricultural and Cooperatives, 2011.

[2] N. P. Pandit and M. Nakamura, "Effect of High Temperature on Survival, Growth and Feed Conversion Ratio of Nile Tilapia, Oreochromis Niloticus,” Our Nature, Vol. 8, 2010, pp. 219-224.

[3] A. T. Duy, J. Scharama, A. V. Dam and A. J. Verreth, "Effects of Oxygen Concentration and Body Weight on Maximum Feed Intake, Growth and Hematological of Nile Tilapia, Oreochromis Niloticus,” Aquaculture, Vol. 275, 2008, pp. 152-162. http://dx.doi.org/10.1016/j.aquaculture.2007.12.024

[4] N. T. Handisyde, L. G. Ross, M.-C. Badjeck and E. H. Al-lison, "The Effect of Climate Change on World Aquaculture: A Global Perspective,” Department for International Development, 2006.

[5] J.H. Matthews, "Anthropogenic Climate Change Impacts on Ponds: A Thermal Mass Perspective,” BioRisk, Vol. 5, 2010, pp. 193-209. http://dx.doi.org/10.3897/biorisk.5.849

[6] L. Touchart and P. Bartout, "Thermocline in Pond: A New Typology by the Study of Continuous Water Temperature Measurement," Proceeding of the Conference of the Water Resource and Wetlands, Tulcea-Romania, 1416 September 2012, pp. 27-32.

[7] C. D. Boontanjai, “Algal Growth Control in Solar Pond,” KKU Engineering Journal, Vol. 16, 1989, pp. 90-97.

[8] W. Y. B. Chang and H. Ouyang, "Dynamics of Dissolved Oxygen and Vertical Circulation in Fish Ponds," Aquaculture, Vol .74, 1988, pp. 263-276. http://dx.doi.org/10.1016/0044-8486(88)90370-5

[9] APHA, "Standard Method for the Examination of Water and Wastewater," 15th Edition, American Public Health Association, Washington DC, 1980. 